[Otros]

\title{
Nuria Claver: una poética del corazón recóndito de la luz
}

Nuria Claver: poetics of the deepest heart of the light

\author{
Alberto Ciria \\ Instituto Filosófico Reinhard Lauth (Alemania)
}

\begin{abstract}
RESUMEN
En la oscuridad no se ven las cosas, pero la oscuridad misma sí que es visible, mientras que la luz, bajo la que todo se ve, es ella misma invisible. La iluminante «luz de noche» es un vacío transparente que puede llegar a conocerse con un tipo de conocimiento, llamado «hábito», que recuerda a la memoria.

PALABRAS CLAVE

LUZ; NOCHE; MEMORIA; POÉTICA
\end{abstract}

\begin{abstract}
In darkness things cannot be seen, but darkness itself is visible as empty, while light, which allows everything to be seen, is itself invisible. The illuminating «light of night» is a transparent emptiness, which can be known with a kind of knowledge, called «habit», that resembles memory.
\end{abstract}

KEY WORDS

\section{LIGHT; NIGHT; MEMORY; POETICS}

La poetisa Nuria Claver Cabrero publicó en 2004 su poemario Luz de noche en la memoria. ${ }^{1} \mathrm{Al}$ margen de que en los poemas que lo componen posiblemente se reflejen también experiencias personales, que podrán ser más o menos universales pero que el lector como mucho solo podrá conjeturar, este poemario es, como toda buena poesía, una meditación sobre el propio acto poético, sobre su génesis y su sentido, y sobre el ministerio

1 Nuria Claver, Luz de noche en la memoria, Madrid, Huerga \& Fierro, 2004.

Claridades. Revista de filosofía 12/2 (2020), pp. 225-258

ISSN: 1889-6855 ISSN-e: 1989-3787 DL.: PM 1131-2009

Asociación para la promoción de la Filosofía y la Cultura (FICUM) 
de la lírica. La poética siempre subyace a los poemas, que son los que nos hablan, y normalmente hay que buscarla detrás o por debajo de ellos. Pero hay poemarios cuyo carácter de automeditación poética es muy resuelto. En estos casos los poemas parecen ensimismarse, invaginarse, absorberse en sí mismos. No son florecimientos en la superficie de una lírica subterránea, sino ecos de fuerzas poéticas inicialmente silenciosas pero que en su reverberación se vuelven palabras. Así sucede con Luz de noche en la memoria.

\section{INTRODUCCIÓN: VERSO Y LATIDO}

«El corazón es una puerta que se cierra a la memoria», dice el verso en cuatro anapestos de Nuria Claver Cabrero, el único que, como si fuera él mismo un latido, se reitera en su poemario Luz de noche en la memoria.

El verso tiene esta métrica porque el corazón late en anapestos sincopados: dos sílabas átonas y una tónica, una sístole percutiente preludiada y prolongada por una diástole larga, porque la expansión demanda distensión mientras que la contracción requiere ímpetu y busca reclusión. El corazón late en verso.

Semánticamente el verso es equívoco. Aún no sabemos si el corazón se cierra dejando afuera la memoria o si el corazón es el acceso a la memoria o incluso la memoria misma, en la que nos encerramos. Quizá el verso no sea equívoco en su sintaxis sino en su léxico, si es que, como parece, hay dos tipos de memoria: una que se parece a la atención y otra que se parece al letargo. Y quizá la reiteración del verso obedezca precisamente a que en sus dos apariciones la memoria tiene significados respectivamente diferentes, lo cual es sugerido ya tanto por la distribución de ambos versos en distintas partes del poemario como por el encabalgamiento en la repetición.

Pero tanto en un caso como en otro sabemos ya que el corazón es una puerta que se cierra, es decir, un claustro en el cual podemos ingresar. Ahora bien, sólo podemos ingresar porque no estamos permanentemente en él. Entramos en el corazón y salimos de él y, tanto si estamos dentro como si estamos fuera, unas veces olvidamos el otro lado, en una inconsciencia que ora es letargo ora es atolondramiento, y otras veces nos lo hacemos presente como el lugar donde no estamos, en un distanciamiento que ora es añoranza que empaña la evocación ora es transparencia que despeja la visión. 
Lo transparente es invisible y lo más difícil de percibir y entender es lo sencillo. Como esos fumadores que sienten ahogo en el aire puro de montańa y solo respiran a pleno pulmón en ambientes enrarecidos, nuestra mente solo parece funcionar a gusto en lo complejo y tiende a soslayar lo demasiado simple y evidente. La sencillez está en la profundidad y las ultimidades siempre son simples.

Pero aparte de que nosotros tendemos a pasar por alto lo más manifiesto y de que lo que más está a la vista es muchas veces lo último en ser visto, el ser quiere unas veces la patencia y otras veces el ocultamiento. El sentido es la verdad del ser. Hay sentidos que para ser íntegros necesitan mostrarse y ser tenidos en cuenta, porque ser sabidos forma parte de ellos y el desconocimiento los hace indigentes. También hay sentidos cuya integridad sólo se preserva en el recato y la reserva, porque la exhibición los vulnera y el ser sabidos los manosea. Y finalmente hay sentidos que no sólo buscan ocultarse, sino que consisten esencialmente en ocultamientos, y éstos son los más invulnerables: si la esencial fragilidad del ser se cifra en la permanente posibilidad de extinción, si ser es ser vulnerable y todo cuanto existe es dañable, entonces nada más inmune que la inexistencia y nada más protector que la apariencia de no ser. Estos sentidos esencialmente ocultos, mientras aún no han sido vulnerados con su exhibición, gustan de preservarse desapareciendo bajo pantallas que fingen ser topes para despistarnos en nuestra sed de trasfondos. En unas ocasiones desaparecen tras la alegre vistosidad de apariencias de frondosa vida, que nos invitan a gozarnos de ellas demorándonos y quedándonos ahí. En otras, tras el aburrido deslucimiento de lo hermético impenetrable, que nos invita a rehuirlo y no indagar más. $Y$ en ocasiones también tras la incontrolable inmensidad de un horizonte que nos absorbe aturdiéndonos y apabullándonos como una advertencia y una amenaza.

Tan pronto advierto una amable senda

fácil de andar

como me sorprendo frente a un mar

donde no existen islas fabulosas

ni tranquilos puertos donde descansar el ánimo²

2 Ibídem, p. 17. 
Y sin embargo, pese a todo el solazoso deleite que ofrecen, pese a todo su cierre y carácter críptico, o pese a toda su vehemencia y sublimidad, esos fenómenos no son más que espectáculos que pueden ser trascendidos.

\section{FRONDOSOS ÁRBOLES RODEABAN LA CASA}

OCULTA TRAS UNA MURALLA DE HOJAS 3

¿Qué habrá detrás de la colina,

del sol, de sus hirientes resplandores? ${ }^{4}$

Todo poema es un pronunciamiento de sentido. La poesía, ya sea proclamación o confesión, manifiesto o sinceramiento, siempre es pronunciamiento. De acuerdo a los tipos de sentido y a cómo se comportan con nosotros, según si se nos ofrecen o nos rehúyen, hay poéticas de la patencia, de la transparencia y de los mensajes netos, sólo comprensibles en sus univocidades. Y hay poéticas de la latencia, de los trasfondos, de los sentidos que se ocultan tras apariencias que unas veces serán engañosas por exuberantes y otras veces inescrutables por crípticas, pero que otras veces también serán amables y encantadoras. Una de estas poéticas es la que, expresada ya en su título, late en Luz de noche en la memoria.

Este poemario de Nuria Claver Cabrero se comprende cuando de pronto sus palabras parecen cobrar un doble sentido, como si se abriera una trampilla que sacara a la luz el significado profundo que hasta ahora había estado tapado por el significado aparente.

Tras las vistosidades aparentes, ese sentido latente solo se revela a «los ojos que están tras de mis ojos». 5

El segundo apartado del poemario se llama «Espejo en el vacío». Este título se puede tomar como metáfora de un arte de visibilizar que no se funda en razones. Hacer ver porque sí, sostener lo manifiesto desde un fondo oscuro, ser recóndita fuente de significados, bombear sentido desde un enclaustramiento que por vesánico o por mágico desafía la sensatez: así se puede definir la función tanto del corazón como de la poesía o de la luz.

Aún puedo imaginarla rodeada de noche

\footnotetext{
3 Ibidem, p. 11.

4 Ibidem, p. 23.

5 Ibidem, p. 34.
} 
de sinrazón, de irrealidad; abandonada

al decir de sus delirios; rendida

ante el mágico invisible ${ }^{6}$

\section{El TÍTULO: «LUZ DE NOCHE EN LA MEMORIA»}

\section{II.1. LA LUZ COMO NOCHE}

«Luz» es, semánticamente, un término equívoco. Con esta equivocidad se corresponde una dualidad de términos tanto en griego ( $\pi \tilde{v} \rho$ y $\varphi \tilde{v} \varsigma$ ) como en latín (lux y lumen). «Luz» como $\pi \tilde{v} \rho$ y lux es la fuente de luz: el foco, que es puntual. El paradigma de luz como foco es el sol. «Luz» como $\varphi \tilde{u} \varsigma$ y lumen es la iluminación radiada por el foco, el espacio iluminado, la zona donde hay luz expandida desde su fuente: la claridad o el claro, que es un ámbito. El paradigma de luz como claro es el día.

Mentalmente podemos disociar sol y día, puesto que de hecho son distintos. Sin embargo, en la experiencia no podemos desvincularlos, ya que uno es consecuencia e incluso manifestación directa del otro.

Pero también la luna iluminada, a modo de espejo, es un foco de luz, pues la luz refleja asimismo alumbra. Y tanto mentalmente como en la experiencia la luna está disociada del día, pues su campo de aparición es la noche. Así se puede decir que la noche es el acceso al foco de luz depurado y refinado de su irradiación. Metafóricamente la noche es el sol sin día, la vía que conduce al manantial sin remontar el torrente. La noche es la luz abstracta o la abstracción de luminosidad como vía hacia el foco, la evidencia del foco luminoso alumbrándose a sí mismo. La noche es el filtro que acendra la luz como foco, la cámara recóndita donde la pura luz preserva y a la vez revela su intimidad más inmanifestable.

En un sentido físico la luz es la radiación energética que, como si fuera un hechizo, se proyecta desde fuera sobre las cosas haciéndolas visibles y retirando la oscuridad que las envuelve. Esta luz deja intactas las cosas y sólo injiere en su entorno. En un sentido poético la luz es el demiurgo que, como si fuera un ensalmo, prende las cosas desde dentro encendiéndolas, sacándolas de la nada al ser y dándoles esa especie de vida ontológica de la que participan incluso los entes inertes y que consiste en el puro acto de existir. Esta luz es una reanimación que hace que las cosas se recobren a sí mismas despertando del letargo de no ser. El ser despierto se exhala dando

6 Ibidem, p. 48. 
lugar al entorno. En el primer caso, el espacio iluminado, empapado de luz, la retransmite haciendo visibles los seres que él alberga. En el segundo caso, los seres encendidos, irradiando luz como reflejos del foco, hacen visible el espacio que ellos mismos despliegan como auras, como si el espacio fuera el aliento que espira el ser. La diferencia entre estos dos casos se corresponde con la diferencia entre hechizo y ensalmo.

El hechizo, emparentado etimológicamente con «hacer» y con «ficticio», se lanza sobre los seres desde fuera. El ensalmo, emparentado etimológicamente con "salmo», prende a los entes encendiendo el ser en su interior.

Pero tanto en un caso como en otro, tanto si el encantamiento de la luz es un hechizo o un ensalmo, tanto si la luz se proyecta desde fuera o prende desde dentro, tanto si retira el velo de oscuridad que envuelve a los seres como si los hace exhalar luminosidad como un hálito ontológico, la propia luz, precisamente por ser potencia de visibilidad, no es ella misma visible. Visibilidad es lo mismo que opacidad, mientras que lo que hace visible es la transparencia. Así es como se puede decir que la luz en sí misma, no en su irradiación lumínica sino como foco luminoso, es una noche, o que la noche es lo que queda cuando los seres iluminados se retiran dejando todo el espacio a la pura «epifanía» majestuosa de la luz ; que es un corazón latente de luz el que activa los latidos del pulso que mantiene viva la patencia de lo iluminado; que en pleno esplendor de lo visible la luz es introvertida; que la luz es para sí misma una noche; que el acto lumínico es el sacrificio por excelencia; que fuera de lo iluminado la luz no se contempla como una presencia, sino que se evoca como una ausencia; y que, por tanto, la facultad que tenemos para hacer presente intelectivamente -ya que no sensiblemente- la luz es una especie de memoria, que muy bien se puede definir como órgano de captación de ausencias e inapariencias a través de evocaciones.

VUELVO a la ausencia escrita en mis ojos

la ausencia que he sido

la ausencia que soy ${ }^{8}$

7 Ibidem, p. 73.

8 Ibídem,p. 58.

Claridades. Revista de filosofía 12/2 (2020) 


\section{II.2. LA NOCHE COMO MEMORIA}

«E-vocar» significa llamar para hacer salir, concretamente desde dentro de nosotros mismos, desde ese encerramiento donde lo una vez conocido duerme su letargo en la noche del inconsciente. Unas evocaciones son meras reactivaciones o reencendidos de contenidos cognoscitivos almacenados en el preconsciente. Otras son recuerdos, que son vivencias sacadas del pozo de la memoria. Pero hay evocaciones donde lo rememorado no sobrevive al ser sacado del inconsciente, sino que exige que nosotros mismos entremos en él para encontrarlo vivo en su hábitat. Estas evocaciones son ensimismamientos, concentraciones creadoras en la magnética sima del inconsciente que abisma y difunde. Nos sumen en una «absorción desveladora». Y es que la concentración mental, que es una llave que abre puertas, cuando es muy intensa se asemeja a la inconsciencia, y así salimos de ella como si despertáramos de un sueño.

Esa sima de conocimiento que en sentido muy lato se puede llamar «memoria», en filosofía se ha llamado a veces «thesaurus» y también «hábito». «Hábito», lo tenido, procede del latín habere, de donde también procede «habitar». Tanto como una posesión, la memoria es una habitación en cuya puerta unas veces golpeteamos para hacer salir, en la que otras veces entramos para tomar y sacar, pero también en la que otras veces entramos para quedarnos un rato dentro y participar, junto con lo que habita en ella, de la estancia cerrada. En este sentido la memoria es un santuario, que no es tanto el sitio donde no se debe entrar cuanto el sitio de donde no se debe sacar lo que hay dentro de él.

Conocer es siempre traer a la luz. Unos contenidos cognoscitivos son indiferentes al movimiento que los saca a la luz, ya sea iluminando las tinieblas inhabitadas que arropaban su letargo, ya sea desenterrándolos de esos aluviones naturales sedimentados que constituyen lo ignoto o desescombrándolos de esas ruinas de la historia que conforman el olvido. Otros contenidos cognoscitivos anhelan ser sabidos, bien porque ser conocido es muchas veces un gozo, bien porque dar a conocer es en ocasiones un acto de justicia. Pero también hay contenidos recelosos del conocimiento, y a esos les gusta esconderse. No se los puede sacar a la luz del conocimiento público sin hacerles violencia, una violencia que puede falsearlos y hasta desintegrarlos. Sino que exigen que nosotros entremos en ellos con la vela del conocimiento privado. Tales intelecciones parecen a veces escondites y 
escondrijos, a veces retiros y claustros, y a veces santuarios y sagrarios. Sólo con sumo tiento podremos entrar en ellos. La luz, que se trasparenta para hacer diáfanas las opacidades, es la clausura por antonomasia.

Entrar en una clausura es por sí mismo una consagración, la investidura de una destinación superior, que exige a cambio una dura ascesis de depuración. Entrar en la clausura de la luz para conocer el arcano de la invisibilidad que hace visible exige hacer abstracción de todos los objetos y renunciar a toda pretensión apropiadora. La noche es la ascesis de la luz.

La abstracción, igual que la belleza, no es un término sino una vía: una vía de depuración y ascesis. Al final de esa vía están las esencias, que no tienen por qué ser ellas mismas abstractas, sino que también pueden ser las almas de las cosas. Lo sencillo siempre está al final del camino, pero ese camino exige desprenderse de todas las complejidades en las que nos sentimos cómodos, igual que el fumador se ahoga en el aire puro de montańa y necesita el aire enrarecido para respirar a pleno pulmón. La abstracción, como toda ascesis, es exigente, y en este sentido se puede decir que es cruel, como también puede serlo la belleza y la pureza.

\section{II.3. LA MEMORIA COMO CORAZÓN}

El corazón no es lo que se enlaza, sino lo que hace enlazarse. Como órgano, el corazón es motor y a la vez lugar de constante transmisión, donde venas y arterias, en direcciones contrarias, permanentemente se encuentran y separan para seguir transmitiendo la sangre.

\section{II.4. El CORAZÓN COMO BUHARDILLA}

Hay lugares inicialmente anodinos que luego quedan señalados cuando en ellos se ha producido un acontecimiento muy cargado de destino. Ningún acontecimiento más cargado de destino que la muerte. Por eso el sitio en el que muere alguien, por muy anodino que hubiera sido hasta entonces, se convierte en un lugar distinguido: la cama anónima de un hospital o un punto cualquiera de la acera gris o del gris asfalto. Se ponen flores en los puntos donde ha muerto alguien, sobre todo si la muerte ha sido violenta. Pero no son las flores las que señalan el sitio. Ellas se limitan a anunciar y a hacer visible que lo que realmente ha señalado el sitio ha sido el fallecimiento. Lugares así se convierten a veces en destinos de peregrinación. También los lugares donde ha tenido lugar un acto creativo muy intenso quedan señalados por ese mismo acto. 
Aparte de esto, hay otros lugares que por su ubicación o por su estructura parecen convocar al destino o semejan ser propicios para una concentración suya. Esos lugares también pasan a quedar señalados después de que el destino se ha presentado en ellos, pero a diferencia de aquellos otros sitios anodinos que en nada lo anunciaban ni permitían presagiar su advenimiento, estos lugares eran ya previamente por sí mismos convocatorias de destino, es decir, lugares predestinados e inspiradores. Muchas veces los lugares predestinados e inspiradores no lo son manifiestamente, sino solo para quien está sintonizado con ellos. Tales lugares acaban siendo santuarios recónditos. Un sitio así es la buhardilla.

Las cámaras del corazón, que son las aurículas y los ventrículos, son oblicuas. Una cámara oblicua es una estancia donde no hay distinción entre pared y techo, y eso es una buhardilla. El abuhardillamiento de sus cámaras le da forma al corazón. Las buhardillas son cordiformes. La buhardilla es una cámara del corazón. Igual que en la aurícula la sangre refluye y vuelve a manar, en la buhardilla la vida privada se repliega y rehace antes de volver a extroverterse. La vida privada que se retira al claustro de la buhardilla no es la vida familiar, sino una vida íntima que puede estar más allá de lo doméstico y ser inasequible a ello. Por eso a veces la buhardilla llega a resultar arcana, misteriosa y siniestra.

La buhardilla es el piso de arriba, donde toda la vivienda converge, y que a la vez le da techo y amparo; es el nivel desde donde se preside con un vistazo único la pluralidad de pisos y habitaciones, mientras que en los pisos inferiores sólo se tienen visiones fragmentarias de la casa. La oblicuidad del techo abuhardillado simboliza la tensión de lo disperso hacia una convergencia superior.

$\mathrm{Al}$ mismo tiempo la buhardilla es el último piso al que se accede. Es el nivel más apartado y desasido del fundamento y del calor de la tierra y el más cercano y expuesto a la salvación y a la intemperie del cielo. La subida a la buhardilla es un ascenso ascético en lo que tiene de fatigoso y de renuncia a lo doméstico, pero liberador en lo que tiene de depurador y desgravitante. Si la casa es una proyección o una materialización de la psique humana, la buhardilla es un nivel de supraconsciencia que vela por la conciencia habitual y la resguarda de la intemperie de la inconsciencia irreversible, siendo al mismo tiempo inasequible a esa conciencia ordinaria. 


\section{LA PORTADA: VENTANA DE LA BUHARDILLA}

La luz hace ver las cosas a costa de ser ella misma invisible. Por eso en sentido transferido se puede decir que la luz es oscura, de modo que la pura luz, a diferencia de los objetos iluminados, bien se puede designar con el epíteto «luz de noche», a diferencia del «anochecer», cuando no se ve nada porque falta la luz. En la portada del libro, bajo el título aparece la fotografía de una ventana cerrada. Supuestamente es la ventana de la buhardilla. Gracias a su opacidad e impenetrabilidad la ventana refleja como un espejo las ramas del jardín que rodea la casa, de modo que los cristales hacen visibles unas ramas que no veríamos si no se reflejaran en ellos. La luz ilumina siendo invisible y la ventana refleja haciéndose opaca. Lo que todavía no vemos es «la noche de la luz» ni «el interior de la ventana». ¿Es la «memoria» a la que alude el título ese «interior de la ventana» donde se guarda «la noche de la luz»?

A su vez, la propia portada del libro es metafóricamente una ventana opaca que al ser abierta nos da acceso al interior de libro, y figurativamente al interior de la habitación y quizá a esa "memoria» donde se guarda la «noche de la luz» o la «luz de noche».

La fotografía de la poetisa en la solapa de la portada, que muestra una mirada callada, sugiere una evocación silente que parece compartir ese mismo sentido. Evocar significa «llamar a comparecencia», y por tanto «hacer aparecer», es decir, "hacer visible». La mirada evocadora retraída en un gesto callado se asimilaría así a la luz invisible y a la opacidad reflejante. Cuando el lector sostiene el libro en las manos siente como si hubiera una complicidad entre la foto de la ventana en la portada y la foto de la poetisa en la solapa.

\section{EL INTERIOR DEL POEMARIO: LA BUHARDILLA}

IV.1. Puerta de entrada

El primer apartado de los tres que componen el poemario lleva por título «Primera ausencia». Aunque ese título quizá connote experiencias autobiográficas de fondo que el lector podrá como mucho conjeturar pero que en último término le resultarán inaccesibles, de hecho denota una primera confrontación con el sacramento poético. La ausencia del poeta en el mundo tiene el mismo sentido que la invisibilidad de la luz en lo visible: es una ausencia fundante y ocultadora. Tanto si el poeta se consagra a esa 
ausencia de una vez para siempre como si repetidamente entra y sale de ella (quizá porque la estancia en la ausencia es demasiado exigente y requiere reposos), el ingreso en ella no se produce por sí mismo ni incidentalmente, sino que es fruto de una resolución madurada. La "primera ausencia» alude tanto al potencial poeta puesto ante la decisión de asumir el ministerio poético como al iniciado que recién acaba de tomar la resolución. En los poemas de este primer apartado trasluce una descripción objetiva, y por tanto todavía distanciada, de la tarea poética. La exposición objetiva de esa tarea es necesaria porque una decisión madurada exige un conocimiento fundado de aquello a lo que uno tiene la opción de resolverse. Esta exposición ocupa todo el primer apartado hasta el penúltimo poema, en el cual se pronuncia con una sola palabra la resolución como un voto: la palabra existencial por excelencia, «Soy».9 En el último poema, después de que el voto ha sido pronunciado, se cumple en un peculiar desdoblamiento entre resolución y acto.

En sentido espacial, ausencia es reclusión, y una metáfora espacial del enclaustramiento es la buhardilla. Resolverse a la ausencia es encerrarse en la buhardilla. La buhardilla es un espacio vacío que sin ser confortable tampoco es inhóspito. Habitar en ella no es tanto un reto cuanto una ascesis. La buhardilla tiene una habitante, llamada «Nadia». ${ }^{10}$

«Nadia» casi se lee como una alusión a «nadie». Como nombre propio, «Nadia» no significa que dentro no hay nadie, sino que dentro hay alguien que no tiene nombre. No lo tiene porque ese alguien es justamente quien da los nombres. Bautizar es hacer ser nombrando, darles a las cosas su ser al designarlas. Cumplir ese acto verdaderamente sacramental es el ministerio del poeta o de la poetisa. Igual que para hacer visibles las cosas la luz tiene que hacerse ella misma nocturna e invisible, igual que para hacer ver reflejando la ventana tiene que hacerse ella misma impenetrable y opaca, e igual que para evocar la mirada tiene que encerrarse en un mutismo, así también quien asigna los nombres, es decir, el poeta o la poetisa, tiene que ser anónimo o llamarse «Nadie»/«Nadia». "Ahora que las palabras no tienen voz /me atreveré a decirlas». ${ }^{11} \mathrm{Al}$ margen de las experiencias biográficas que pueda haber de fondo, si referimos el título del apartado, "Primera

\footnotetext{
9 Ibídem,p. 18.

10 Ibídem,p. 11.

11 Ibidem,p. 12.
} 
ausencia», a la misión poética, se puede interpretar en el sentido de que la función de hacer presentes las cosas, ya sea iluminándolas, reflejándolas, evocándolas o nombrándolas, exige del poeta o de la poetisa su propia reclusión y ausencia. Solo el anónimo («Nadia») nombra, solo lo opaco refleja, solo el ausente crea sitio para la frondosa comparecencia, solo el silente da voz a los seres. ¿Cómo no asimilar la poetisa a la luz, que ofrece el sacrificio de su invisibilidad para hacer visibles los seres?

Al hablar de lugares predestinados vimos que hay dos sentidos de señalar: señalizar y distinguir. La señalización es extrínseca, mientras que la distinción es inherente. Las flores señalizan puntos que quedaron distinguidos cuando un acontecimiento se produjo en ellos. Las flores son el signo de la distinción, no su causa. En los poemas escritos, esa función señalizadora la cumplen las mayúsculas.

FRONDOSOS ÁRBOLES RODEABAN LA CASA

OCULTA TRAS UNA MURALLA DE HOJAS

DESDE UNA DE LAS BUHARDILLAS

NADIA CONTEMPLABA ESE JARDÍN

QUE ALGUIEN LLAMÓ DESHABITADO ${ }^{12}$

No es que la frondosidad cause el efecto posterior de tapar lo que hay tras ella. Más bien, en sentido inverso, la frondosidad es un don del ocultamiento y solo la reclusión, simbolizada por la buhardilla, hace posible la boscosa espesura.

Estoy en esta noche

y la cárcel de mis días habla de ausencia

Ahora que las palabras no tienen voz

me atreveré a decirlas:

Son un feliz aliento para la tenaz fatiga

velan la incesante oscuridad

recuerdan su cadencia

Atesoraré todo el silencio

12 Ibídem, p. 11. 
No cruzaré la puerta ${ }^{13}$

Cada amanecer soy diferente

a la que horas más tarde despierta y ve la luz ${ }^{14}$

Podría acercarme para ver, mas...

Quiero esta lejanía

donde habita la memoria que jamás logré desentrañar

Amo esta penumbra

y a ciegas la recorro siempre tras un mismo paisaje:

los senderos de mi voz - eterna música-

los latidos de mis pasos hacia un profundo corazón ${ }^{15}$

La fuerza poética que despierta a los seres aletargados llamándolos por sus nombres propios o que incluso quizá los genera al bautizarlos es a su vez reacia a toda figura y a todo molde, y se parece más a la espuma, al oleaje, a un espejismo o a una polvareda. Inconsistente y amorfa para nuestros sentidos cotidianos, acostumbrados a figuras que ya han sido hechas, esa fuerza poética, asimilable por su potencia a una marejada o a un huracán, al anidar en la poetisa y enseńorearse de ella le permite pronunciar un «Soy» $\sin$ «yo»:

No cesa este oleaje

Estoy envuelta en niebla

No cesa esta impaciencia

Me alejo

Soy:

una mirada

océano profundo

noche y mar tejiendo un espejismo

los días de mis días

-reflejos de auroras muertas-

un huracán

$\mathrm{y}$ mis ojos polvorientos ${ }^{16}$

13 Ibidem,p. 12

14 Ibídem,p. 13.

15 Ibidem,p. 14.

16 Ibidem,p. 18. 
Esos «ojos polvorientos» dibujan los contornos, y así crean las figuras de los seres que la palabra poética ha despertado del letargo o ha generado de la inexistencia:

\section{UNA LUZ DORADA CRUZABA ENTRE LAS SOMBRAS ${ }^{17}$}

la luna rayará de blanco un crisantemo ${ }^{18}$

Estoy bordando un sol sobre la tierra como si los ojos que están tras de mis ojos vieran mis manos serpear entre la hierba ${ }^{19}$

y sé que estuve ahí

bordando un sol sobre la tierra ${ }^{20}$

Así dibuja hacia fuera la mirada poética los contornos de los seres: como un rayo de sol recortando sombras, como un rayo de luna delineando pacientemente en blanco inescrutables exuberancias para deslindarlas del negro nocturno o como una mano peinando la hierba enmarańada. Pero adentro todo es innombrable, indescifrable y difuso:

Quiero y no quiero hablar de la tristeza

de los ecos ahogados en la memoria

¿Cómo descifrar esta melancolía?21

El silencio que me inunda

presume que es mejor callarlo todo ${ }^{22}$

Podría comenzar a hablar

pero mi voz... ¿ ¿me desconoce? ${ }^{23}$

Quedamos yo y mi penumbra ${ }^{24}$

17 Ibídem,p. 21

18 Ibidem,p. 25.

19 Ibidem,p. 34.

20 Ibídem,p. 43

21 Ibidem,p. 28.

22 Ibídem,p. 29.

23 Ibidem,p. 33.

24 Ibídem, p. 38, 
Ahora soy el terror

Conozco los enigmas ${ }^{25}$

Y si causalmente un rayo de luz se filtra desde fuera en la penumbra, no encuentra dentro nada que delinear y se queda como atónito y sin saber qué hacer:

La luz que hoy entra por el amplio ventanal se quedará ahí

apoyada en la fachada gris oscuro de la casa ${ }^{26}$

A lo largo de todo este primer aparatado, "Primera ausencia», se ha explicado en qué consiste el sacramento poético como el acto de otorgar ser y visibilidad al precio de recluirse, de perfilar contrastados claroscuros a costa de difuminarse en incierta penumbra (de «subrayar» a costa de hacerse «hálito» que rebasa la «figura»), y se ha hecho saber que a resultas de una decisión tal ministerio sacramental se puede asumir, quizá vitaliciamente como una consagración, aunque su ejercicio se practique en tiempos señalados, marcados por el tránsito por la puerta de la buhardilla en uno u otro sentido. En el penúltimo poema se pronuncia el voto de asunción del sacramento poético:

Entraré

No oigo los pájaros

Duerme hasta el silencio

No queda más rumor que el de mis pasos

Diré adiós a la luna ${ }^{27}$

Y en el último poema, esa promesa pronunciada se cumple. Entre pronunciamiento y cumplimiento ha habido un cambio de perspectiva de la primera a la tercera persona, y un cambio de tiempo del futuro al pasado, quizá porque el relato del cumplimiento oscila entre el presagio y la evocación. La intangibilidad de ambos, es decir, la falta de solidez del preludio y la evocación, es connotada con la cursiva:

25 Ibidem,p. 42.

26 Ibidem,p. 20.

27 Ibídem,p. 44 
Iba, segura de su búsqueda

dispuesta a subrayar la superficie

Un hálito de esperanza

envolvía su figura de hada incauta ${ }^{28}$

El espacio vacío de la buhardilla sin ser inhóspito tampoco es confortable, y la estancia en ella es ardua. Son necesarios los reposos, entrar y salir de la buhardilla.

\section{IV.2. INTERIOR DE LA BUHARDILLA}

El segundo apartado del poemario lleva por título «Espejo en el vacío». La imagen del espejo suspenso en la nada es una metáfora del poeta o de la poetisa según su función de «ausencia reflectante». Otra imagen metafórica con el mismo sentido era la fotografía de la portada que mostraba la luna de la ventana cerrada: la transparencia que tenía que opacarse para tornarse espejo y, así, visibilizar reflejando. Espejo en el vacío, ausencia reflectante, foco invisible, opacidad reflejante y hasta la propia buhardilla como cuarto de escribir son metáforas sinónimas que componen una letanía al poeta o a la poetisa nombrándolos por su función de hacer ser diciendo.

«Espejo en el vacío» se enmarca entre dos poemas escritos en cursiva: respectivamente una revivencia y una evocación. La evocación se distingue de la revivencia en que el evocador no se introduce en la escena que se le proyecta, sino que, absorto en la evocación y olvidado de sí mismo, meramente la contempla desde fuera, mientras que al revivir una escena uno sí se mete en ella. Porque el evocador está olvidado de sí mismo, salir de la evocación equivale, de alguna manera, a despertar. Como ya sucediera en «Primera ausencia», la cursiva expresa plásticamente la inconsistencia del recuerdo, tanto si es revivencia como evocación, no por su irrealidad sino por su inmaterialidad. Como si al hacer ser diciendo el poeta transfiriera su propia sustancia a los seres que nombra, y al sufrir él mismo menoscabo de consistencia su propia existencia personal se mutara en reminiscencia, es decir, en vaho:

VUELVO a la ausencia escrita en mis ojos

la ausencia que he sido

la ausencia que $\operatorname{soy}^{29}$

28 Ibidem,p. 45.

29 Ibídem,p. 58. 
Así como la cursiva evoca la inestabilidad del «vaho» de la reminiscencia, la mayúscula connota la solidez de lo definitorio. Entre ambos poemas recordatorios en cursiva una serie de breves poemas encabezados sentenciosamente por infinitivos sustantivados y con carácter de definición o de glosa marcan el recorrido de ingreso en la buhardilla como viaje espiritual del poeta hacia el centro poético, que al mismo tiempo es el propio trayecto del lector según va pasando páginas y adentrándose en el interior de libro. Los títulos de los poemas componen la siguiente serie: «ENTRAR - VER - SER: PARA DECIR, PARA NOMBRAR, PARA SEÑALAR, PARA COLMAR». A su vez, cada uno de los breves poemas glosa su título.

\author{
ENTRAR: \\ El corazón es una puerta \\ que se cierra a la memoria ${ }^{30}$
}

Estos versos se repiten en los dos primeros apartados del poemario. Con una diferencia: aquí están encabalgados. Este encabalgamiento convierte el poema en un caligrama. El caligrama es una composición poética cuya disposición tipográfica representa el contenido del poema. Así como la cursiva dibuja una inestabilidad y la mayúscula una solidez, el encabalgamiento en dos versos es el dibujo de la hoja de una puerta girada sobre su gozne. Ahora entendemos la diferencia entre escribir la frase «El corazón es una puerta que se cierra a la memoria» en un solo verso o en dos encabalgados. En un solo verso, tomándolo como caligrama, el poema habla de una puerta cerrada, supuestamente porque en el primer apartado la puerta se muestra todavía sobriamente como cerrada, sin abrumar aún al potencial poeta instándolo a cruzarla, sino concediéndole una serenidad, casi hasta una melancolía, para que pueda madurar con tiempo su decisión. A la serena e «indescifrable melancolía» ${ }^{31}$ de la puerta cerrada - «no cruzaré la puerta ${ }^{32}$ - aludían versos centrales de "Primera ausencia».

Separada la frase en dos versos encabalgados, el caligrama dibuja una puerta abierta. Por qué la puerta está abierta nos lo dice el título del poema: «ENTRAR». Con su disposición tipográfica el poema como caligrama glosa su título al esbozarlo.

30 Ibidem,p. 49.

31 Ibidem,p. 28.

32 Ibidem,p. 12. 
Los versos del poema dicen textualmente que el corazón es una puerta que se cierra a la memoria, pero el título y el caligrama nos dicen que el poeta primero tiene que cruzar la puerta, la cual por eso está ahora abierta.

Pero la puerta no ha estado siempre abierta, sino que inicialmente estaba cerrada y se ha abierto ahora, en el paso de «Primera ausencia» a «Espejo en el vacío». Es más: no es que la apertura de la puerta sea una diferencia más que constatamos entre ambos apartados del poemario, sino que el segundo apartado surge precisamente cuando la puerta se abre.

La puerta, al abrirse, insta a cruzarla. Una vez que el poeta la haya cruzado, la puerta se cerrará a la memoria. ¿Qué es la memoria para que pueda quedar tras una puerta cerrada? ¿En qué lado de la puerta se queda la memoria y en qué lado estamos nosotros, los lectores que no acompańamos al poeta en su trayecto sino que leemos después lo que él ha escrito? ¿Y a qué memoria se cierra la puerta, a la del poeta, a la nuestra, o a una especie de memoria impersonal como poso y sedimento del cual surgen luego las diversas personalidades?

En cierto sentido, cuando el poeta ha cruzado la puerta y la ha cerrado tras de sí, ha dejado fuera lo que hasta ahora había sido su vida, que entonces pasa a transformarse en recuerdo: precisamente en ese recuerdo precedente al poema «ENTRAR» con el que comienza el apartado «Espejo en el vacío». Cuando el ejercicio poético no es ocio sino vocación, cuando no es incidental sino esencial, el poeta o la poetisa, al cerrar la puerta, deja atrás su pasado. Habiendo dejado al otro lado de la puerta ya cerrada lo que hasta ahora fue su vida, el poeta se vacía, se convierte en una «ausencia» o se desmaterializa en un "vaho».

¿Pero qué es aquí causa y qué es consecuencia? ¿No sucede más bien al revés, que el poeta tiene que dejar atrás su vida como consecuencia del imperativo de vaciarse que impone el acto poético? El poeta solo puede dar entidad a los seres bautizándolos con la palabra si él mismo se ha desprendido de todo nombre ( $N$ Nadia») y de toda determinación y se ha convertido en vaho, en hueco y en terror. Ese vaciamiento exige o acarrea dejar lo que él fue hasta ahora, y que se conserva en la memoria, al otro lado de una puerta cerrada.

Lo que no sucede es que el poeta, al entrar en la buhardilla movido por la curiosidad, se sorprende al constatar que su vida pasada se ha quedado a la entrada. No se llega a ser poeta por casualidad ni irreflexivamente, sino 
por resolución fundada, y el poeta es muy consciente de la naturaleza de su ministerio antes de haberlo asumido. Precisamente todo el primer apartado del poemario, "Primera ausencia», venía a ser una especie de exposición de los estatutos de la vida poética, que al poeta se le dan a conocer de antemano para que su aceptación o rechazo sea fundado.

En este sentido de la memoria como conservación de lo que se fue, el poeta la deja fuera de la puerta. Pero nosotros, que no acompañamos al poeta en su subida a la buhardilla ni menos aún cruzamos con él la puerta, sí mantenemos el recuerdo de lo que el poeta fue antes de serlo. Es más, su subida a la buhardilla quizá ha sido tan recóndita que nosotros ni siquiera nos hemos enterado de ella. ¡Cómo nos vamos a enterar si la ventana de la buhardilla, para reflejar y visibilizar haciéndose espejo, está cerrada! Y así es como somos incapaces de reconocer al poeta como poeta, y nos parece que es presencia lo que, en realidad, ya no es sino memoria abandonada.

Pero en otro sentido, memoria no es el recuerdo de la vida pasada, sino el conocimiento guardado, reservado, custodiado en un inconsciente latente. Ese conocimiento latente se puede conmemorar. La conmemoración, la evocación y la revivencia son tres maneras de recordar. En la evocación y en la revivencia, quien recuerda saca del recuerdo contenidos para volver a tenerlos presentes. Metáfora de la memoria de la que sacamos recuerdos es el baúl. En la conmemoración quien recuerda no saca, sino que se mete, y no pone recuerdos delante de sí, sino que se adentra y se expone a lo conmemorado. Metáfora de la memoria en la que nos adentramos es la buhardilla.

El baúl de los recuerdos está lleno. La buhardilla de la memoria está vacía. En cierto modo, la propia buhardilla es un vacío. ¿Pero no nos decía el título del segundo apartado que en el vacío hay al menos un espejo? No necesariamente, sobre todo si reparamos en la forma nominal del título del apartado, es decir, en la ausencia de verbo. ¿Cuándo el «espejo en el vacío» no desmiente que la buhardilla está vacía? Cuando el espejo no está en el vacío, sino que el vacío es el espejo. ¿Cuándo el vacío es el espejo? Eso nos lo explica el siguiente poema: «VER».

VER:

Una mirada puede recorrer el universo ${ }^{33}$

33 Ibídem, p. 50. 
La función del espejo es visibilizar, hacer visible. Visibilidad es opacidad: solo vemos lo opaco. Lo opaco es aquello que la mirada no atraviesa. Para la mirada, ver es ser interrumpida en su recorrido. Pero si ver es para la mirada ser interrumpida por lo opaco en su recorrido, ¿̨cuándo «una mirada puede recorrer el universo»? Cuando el universo está hecho de vacío.

El hecho de que la definición del «VER» ocupe un único verso, y no esté partida en un encabalgamiento, ya sugiere con su plasticidad el recorrido ininterrumpido de la mirada.

Hay dos enfoques desde los cuales una mirada podría captar la totalidad del universo. Un observador podría captar en una sola mirada el universo en su conjunto si estuviera situado fuera de él. Una mirada así captaría una panorámica universal. En cierto sentido, la reclusión en la buhardilla es una manera de salirse del universo, de modo que, metafóricamente, desde la buhardilla sería posible lanzar una mirada así.

Pero no haría falta abarcar de un vistazo la totalidad del universo para captarlo en su conjunto si se es capaz de ver el todo en una parte. Lao Zi parece definir la sabiduría como la captación del todo en la parte, o de lo infinito en lo finito, cuando dice en su Libro del Tao que «la persona sabia llega a conocer el mundo sin salir del patio de su casa». También Leibniz dice en su Monadología que cada gota del estanque es a su vez el estanque entero. El cálculo infinitesimal o el cálculo de derivadas que desarrolló Leibniz es precisamente un método para indagar infinitudes en fragmentos acotados. Es verdad lo que dice Antoine de Saint-Exupéry en esta hermosa frase:

La pared del jardín de casa puede encerrar más secretos que la Muralla China, y el alma de una niña está mejor protegida por el silencio de lo que lo están los oasis saharianos por el espesor de las arenas.

No obstante, la frase de Leibniz dice algo más: que el estanque entero está en cada una de sus gotas, igual que en cada fracción de una parábola está la parábola entera. La mirada infinitesimal no capta panorámicas, sino fragmentos, pero dentro de cada fragmento encuentra un mundo interior y a partir de cada fragmento es capaz de reconstruir la totalidad, que incluye también lo externo.

Pero tanto la mirada panorámica como la mirada infinitesimal son miradas que se detienen. Lo visible es lo que interrumpe la mirada. 
Sin embargo, hay una tercera mirada que capta el universo recorriéndolo: la mirada que no se detiene, y que por tanto no capta el universo como visible, sino que lo capta como vacío. ¿Cuándo el universo se capta como vacío? Cuando el universo no es el conjunto de los seres, sino el principio que hace que los seres sean un conjunto, en lugar de una acumulación o de un desperdigamiento. "Universo», del latín uni-versus, significa etimológicamente «lo hecho uno». El universo como principio, o el principio universal, sería entonces lo que hace que todo sea uno. La fuerza unificadora se distingue de los elementos unificados, igual que quien da los nombres tiene que ser anónimo («Nadia») e igual que lo que hace ver tiene que ser invisible (la luz). Diciéndolo metafóricamente, no es que los frondosos árboles tapen la buhardilla, sino que la frondosidad llena la mirada solo gracias a que la buhardilla es un cuarto de reclusión.

¿Entendemos ahora mejor aquellos versos del primer apartado que nos hablaban de árboles frondosos rodeando la casa oculta tras una muralla de hojas, o de lo que queda detrás de la colina y de los hirientes resplandores del sol?

¿Y entendemos ahora mejor el título «Espejo en el vacío»? ¿Acaso vemos el espejo? No: lo que vemos siempre es la imagen reflejada sobre él. Nunca vemos el espejo, porque la imagen reflejada nos lo tapa. ¿Veríamos el espejo si retiráramos la imagen reflejada? Tampoco, porque si el espejo dejara de reflejar entonces también dejaría de ser espejo. Lo tomemos como lo tomemos, el hecho es que nadie ha visto jamás un espejo.

El espejo se esconde tras la imagen reflejada igual que la casa de la buhardilla se esconde tras los frondosos árboles e igual que la nada se esconde tras el todo. «Espejo en el vacío» no significa que en el vacío cuelgue un espejo, sino que el propio vacío hace de espejo, o que el espejo, para serlo, tiene que ser vacío.

A diferencia de las miradas panorámica e infinitesimal, ¿qué capta entonces la mirada que recorre, es decir, la mirada vacía, la mirada de «los ojos que están tras de mis ojos»? Se capta a sí misma. Cuando la poetisa entra en la buhardilla no sólo ve un espejo en un cuarto vacío, sino que ella misma se hace espejo y vacío, «Nadia».

Qué significa para sí mismo ser espejo refractante y visibilizante, vacío fecundo y anonimato dador de nombres nos lo dice el siguiente poema: 
SER:

Deseo inalcanzable

Lugar de los contrarios

Paraje de incómodas creencias

Un solo hueco

y continuamente

estar

cayendo ${ }^{34}$

Los dos últimos versos tienen marcadísimo carácter de caligrama, aún más notorio que en los poemas anteriores. Pero si este poema titulado «SER» es el caligrama de una caída, entonces es que el ser, en algún sentido, es un vacío, o como dice el poema, «un solo hueco». El ser no es entre otras cosas un hueco, sino que no es nada más que un vacío. Pero el vacío no se define aquí como ausencia de objetos, sino como lugar de una caída. Quien cae por el vacío del ser es, obviamente, el poeta. ¿Qué significa que el SER es un «solo hueco» definido además como lugar de caída? Dos cosas. Primero, que al caer por el hueco el poeta tampoco es un ser dentro del vacío (en cuyo caso no habría «un solo hueco», sino un hueco y además alguien dentro), sino que la "caída en el hueco» es una metáfora para decir que el propio poeta se hace vacío: sólo hay «un solo hueco» si el propio poeta se hace vacío. Y segundo, que la conversión en vacío no es una detención, sino un recorrido, lo cual ya sabíamos gracias al poema anterior "VER», que hablaba de la mirada que recorre infinitamente el universo.

Si el ser es el vacío, entonces la caída es sin fin, igual que la mirada recorre el universo sin ser detenida por opacidades. Ahora, al llegar a este poema, se nos aclara una peculiaridad de puntuación que domina todo el poemario y que ya habíamos advertido desde el principio pero que solo ahora entendemos en su sentido: la ausencia de puntos finales al término de las estrofas y los poemas. La falta de puntos finales remarca lo interminable de la caída de un ser hecho vacío y del recorrido de una mirada hecha espejo.

Es evidente que este poema es el caligrama de una caída. Pero entonces el poema se entiende mejor leyéndolo de abajo hacia arriba. Ya sabemos

34 Ibídem,p. 51. 
que el ser, como vacío, es un hueco de caída. El verso anterior describe el vacío como un "paraje de incómodas creencias". Ahora bien, ¿incómodas para quién? ¿Y cómo es que se habla de "creencias», si supuestamente el poeta o la poetisa, al hacerse vacío, ha alcanzado una certeza indubitable, que además solo le ha confirmado ahora lo que ya se le había dado a saber antes de consagrarse al ministerio poético? En todo caso el poeta o la poetisa tiene un «saber terrible». Las «incómodas creencias» son las de quienes no lo hemos acompañado en su entrada en la buhardilla. Por qué esas creencias son incómodas nos lo dice a su vez el verso anterior: porque en el vacío los contrarios se juntan, y eso nos desasosiega a nosotros, que solo nos sentimos a gusto en nuestro mundo de oposiciones bien definidas y a quienes todo lo que no se reduzca a una oposición nos atemoriza. ¿Qué contrarios se juntan en el hueco? Ya nos no lo ha dicho el poema: el ser y el vacío, o el ser y la nada, justamente los contrarios de la oposición suprema, cuya disolución incomoda e incluso espanta a los no poetas.

Leyendo de abajo arriba, hemos llegado ahora al primer verso: «Deseo inalcanzable». Este verso se puede leer desde dos perspectivas: desde la perspectiva del poeta o de la poetisa y desde la perspectiva de nosotros los lectores. Para entender este verso en el contexto de lo antes explicado hay que atender a su literalidad: el verso no dice "deseo irrealizable», sino «deseo inalcanzable». Un deseo que no se puede realizar es al menos alcanzable como tal deseo: alcanzar un deseo es tenerlo. Un deseo inalcanzable es un deseo que no está al alcance como tal deseo, es decir, un deseo que no se puede tener. El deseo inalcanzable es el deseo del vacío. Ni el poeta ni el lector pueden desear el vacío. El poeta no puede desear el vacío porque ya lo es. El lector no puede desear el vacío porque nada sabe de él. En todo caso, el vacío pudo ser un deseo alcanzable antes de que el poeta llegara a serlo, en "Primera ausencia», pero una vez que ha «entrado» en el «Espejo en el vacío» el deseo se ha desvanecido en su realización.

Un poema posterior dentro del mismo apartado habla de los contrarios que se juntan en ese lugar:

AHÍ:

tan lejos como el Principio

tan cerca como el Ahora

como el Nunca tan incierto 
irreal como ese Siempre ${ }^{35}$

Este poema no nombra los contrarios que se unen ni el lugar donde se unen. El lugar no se nombra sino que se señala, y el carácter indicativo del adverbio se enfatiza con los dos puntos: «AHÍ:». La unión de contrarios no se nombra sino que se describe por medio de comparaciones que a su vez solo pueden ser contrarias: lejana como el principio y cercana como el ahora, comparte con el nunca la incertidumbre y con el siempre la irrealidad. ¿Cuáles son esos contrarios que se pueden señalar, que incluso son omnipresentes, ambos cercanos y lejanos, prístinos y actuales, inciertos e irreales, no fechables pero permanentes? Supuestamente el ser y la nada, que en realidad ya han sido nombrados muchas veces en el poemario.

Los dos poemas «VER» $y$ «SER» nos dan por tanto la siguiente «ecuación»: poeta $=$ mirada $=$ espejo $=$ vacío. Además, el poema anterior "ENTRAR» nos ha dicho que el poeta se hace, que se hace por propia resolución, que toma la resolución con plena conciencia de las consecuencias, y que el conocimiento de las consecuencias no lo ha averiguado él por sus propias indagaciones sino que le ha sido comunicado por la existencia poética misma.

Los poemas siguientes nos dirán para qué todo esto. Y además nos detallarán cuáles son esos contrarios que surgen del pozo de la poesía y cuya fusión espantaría a los no poetas.

\section{PARA DECIR \\ que el viento arrasa y acaricia \\ PARA NOMBRAR la lluvia agua sobre fuego}

sobre tierra sobre agua ${ }^{36}$

Estos poemas mencionan los elementos: aire, agua, fuego, tierra. Si de nuevo tomamos los poemas como caligramas, los cuatro elementos aparecen estratificados: aire sobre agua, agua sobre fuego, fuego sobre tierra, y tierra sobre un agua subterránea.

35 Ibidem,p. 59.

36 Ibidem,p. 54. 
Como caligrama, «PARA DECIR» expresa con el único verso la horizontalidad del viento que sopla arrasando y acariciando. Los arrasamientos y las caricias no son perpendiculares, sino paralelos y pegados a la superficie arrasada y acariciada, de modo que no hay desdoblamiento de planos, que es lo que sugeriría el desdoblamiento de la frase en dos versos.

Como caligrama, «PARA NOMBRAR» estratifica los elementos, y con el verso final que habla de aguas subterráneas introduce una circularidad en la distribución. Cuáles son esas aguas subterráneas nos lo dirá luego el tercer apartado del poemario. Y la distribución en círculo nos sugiere que hay tanto un afuera más allá de los elementos como un centro desde el cual ellos se despliegan ordenadamente. Ese afuera y ese centro son lo mismo: el vacío. El vacío es centro porque genera los elementos. Los genera y les da ser bautizándolos, «diciendo» el viento y «nombrando» el agua, el fuego y la tierra. El vacío es afuera porque los elementos, surgidos centrífugamente, no saben de él.

El orden de los elementos, su estratificación de arriba abajo y su circularidad, nos permite orientarnos a quienes vivimos en ellos y por tanto no estamos en el vacío. Ese orden nos resulta "cómodo». Pero es una "creencia» si suponemos que los elementos se constituyen solos sin necesidad de la voz que con el nombre les da el ser. Esa «comodidad» es la «quietud»y la «calma» de las que nos hablan los versos siguientes, y que se opone a la «caída por el hueco». La distribución de los elementos nos permite señalarlos y diferenciarlos:

PARA SEŃALAR la quietud y diferenciar la calma ${ }^{37}$

Pero esa distribución solo es posible después de que los elementos han sido dichos y nombrados.

PARA COLMAR de imágenes

palabra por palabra

hasta sobrevivirlas

por eternizarlas ${ }^{38}$ 
Este poema, que cierra la serie de caligramas definitorios de la estancia en la buhardilla, se basa en dos asimilaciones internas, en dos oposiciones externas y en una paradoja intrínseca. Las asimilaciones internas son imagen-palabra e (imagen-palabra)-eternizar. Las oposiciones externas son col$\mathrm{mar} / \mathrm{vacío} \mathrm{e} \mathrm{imagen/espejo.} \mathrm{La} \mathrm{paradoja} \mathrm{intrínseca} \mathrm{es} \mathrm{eternizar/sobrevivir.}$

Para asignar nombres el poeta se hace anónimo y la habitante de la buhardilla pasa a llamarse «Nadia». Para formar imágenes el propio espejo no debe verse. El espejo se esconde tras la imagen reflejada igual que la buhardilla se esconde tras los frondosos árboles: el escondimiento detrás no es consecuencia, sino causa de la vistosidad delante; el vehemente torrente de imágenes y palabras brota del manantial oculto. Asignar nombres a los seres y visibilizarlos es darles consistencia y durabilidad, y en este sentido «eternizarlos». El poeta, invisible y anónimo, se sale de los nombres y las imágenes y se recluye en un vacío que por un lado es más fugaz que los seres que vemos y nombramos, tan fugaz como una caída, pero que por otro lado es más real por ser fuente de realidad. «Sobrevivir lo eternizado» es recluirse en esa caída que a costa de ser el vacío mismo puede hacerse manantial de consistencia. Es el vacío propio de la boca de la fuente, que no retiene el impetuoso chorro. No es que la vehemencia del chorro reprima a la boca de la fuente, sino que es el recato de la boca lo que hace impetuosa la corriente.

En este segundo apartado aparece todavía el poema que será repetido no dentro del propio poemario, sino en la contracubierta. En el otro poema repetido, la diferencia de sentido en sus apariciones venía marcada por su situación en dos apartados distintos y por el encabalgamiento de la repetición. En este caso el poema se reproduce inalterado, pero las respectivas colocaciones en el segundo apartado y en la contracubierta permiten dos lecturas. Más adelante veremos su sentido en la contraportada. De momento se puede decir que ya la propia repetición denota la circularidad que el poema mismo connota al identificar el hallazgo con la pérdida y la búsqueda, cuyos trasuntos metafóricos eran la identificación de pozo y caída y la de espejo y vacío, y cuyo sentido es la identificación de noche y luz o de nada y ser.

PODRÍAS

buscar eternamente 
eternamente hallar y perder el rastro ${ }^{39}$

\section{IV.3. Paisajes desde la ventana}

«Poemas del regreso» es el apartado más breve, pero también el más denso del poemario. En él se reúnen los poemas más contundentes. A pesar de su concisión, en él se distinguen estas tres partes:

En los tres primeros poemas se recapitula sobre la estancia en la buhardilla.

Desde esa recapitulación se valora de nuevo esa estancia. Esta nueva valoración es una revalorización.

Con la plena conciencia de esa revalorización el poeta o la poetisa se arma para afrontar el regreso.

\section{IV.3.1. RECAPITULACIÓN SOBRE LA ESTANCIA}

Preferible que sólo un día, una mañana

sea noche luminosa ${ }^{40}$

El confinamiento en la buhardilla ha sido duro, como una «cruenta batalla» que deja huellas. ${ }^{41} \mathrm{Ha}$ tenido que soportar pesadumbres («a pesar de los tonos grises de la tarde»), asomarse a la hondura, asumir la soledad y exponerse a la ceguera. Todo eso no se puede sobrellevar indefinidamente. Quizá ni siquiera se pueda soportar más allá de una noche, tanto si esa noche se toma en sentido real como en sentido metafórico. Pero es preferible haber pasado esa noche de pesadumbre, hondura, soledad y ceguera a seguir viviendo en una aparente lucidez que en el fondo no es sino una ceguera inconsciente. Preferible una sabiduría que se paga cara y que en realidad no tiene contenido a una ignorancia que no sabe que lo es porque se disfraza de erudición de banalidades. Preferible que los ojos se quemen en la noche de luz, en la visión de lo iluminador sin lo iluminado, a dejarlos intactos en esa oscuridad en la que solo aparecen objetos y nada más.

Cayó la oscuridad. Aún es de noche

Siempre el mismo río por debajo

no cabe en las manos

39 Ibidem,p. 60.

40 Ibidem,p. 65.

41 Ibidem,p. 73. 
no le alcanzan mis palabras

\section{¡Arrastra! ${ }^{42}$}

La noche se describe con los pares de determinaciones opuestas que también caracterizan la corriente del río: aún y siempre, permanente pero indetenible; no la alcanzamos ni siquiera con nuestras palabras, que llegan más lejos que nosotros, y sin embargo nos llenamos las manos de ella, aunque se nos escurra; no accedemos a ella y en cambio nos arrastra; está por debajo de nosotros y no obstante nos desborda. La noche es un "pájaro» que podemos atrapar y al mismo tiempo una «jaula» que nos cautiva, es inmensa y poderosa como el «mar» y a la vez evanescente como la «espuma», océano y «desierto», "hondonada» y bóveda celeste «sin estrellas», «aurora» $\mathrm{y}$ «niebla». En fin, la noche es «el horizonte».

Los primeros versículos del Génesis son una narración mítica de la separación y la estratificación de los cuatro elementos, que inicialmente estaban indiferenciados. El horizonte será el rejuntamiento ordenado de los cuatro elementos escindidos unos de otros.

Según el Génesis el acto de la creación es, primero, el acto de separar la transparente luz del amorfo mineral extrayéndola de él, y luego, el acto de desdoblar, dentro del mineral, el aire leve y diáfano, el agua fluida y refractante de la tierra densa y opaca.

Aquel desgarramiento primordial que arrancó y extrajo unos de otros luz, aire, agua y tierra, claridad, transparencia, refractancia y opacidad, abrió espacio al despliegue del mundo y al desarrollo de la historia.

Despliegue y desarrollo, inconsciente y hondamente sabedores de su nacimiento en una rotura y de su procedencia de un rompimiento, trabajan en la sutura, que es la costura con que se reúnen los labios de una herida.

La línea del horizonte es la sutura, la cicatriz que marca el rejuntamiento de luz, aire, agua y tierra, el reencuentro de cielo, nubes, mar y orilla, después de que fueran arrancados unos de otros en el desgarramiento primordial de la creación.

La cicatriz guarda la memoria del desgarramiento y el horizonte guarda la memoria de la creación.

42 Ibídem,p. 66. 
Mientras el despliegue y el desarrollo trabajaban aun sin saberlo en la sutura, el mundo y la historia estaban abocados al horizonte. Una vez cerrada la sutura, cuando, conducido por la tierra, el mar se ha rejuntado con el cielo y el despliegue y el desarrollo han llegado a su fin, mundo e historia han quedado englobados en el horizonte. El magma se ha hecho bóveda.

El horizonte es un beso de reencuentro de luz, aire, agua y tierra al cabo de una despedida tan antigua que llegó a ser olvidada y de una separación tan prolongada que dio cabida al mundo y a la historia, despedida y separación que ahora son evocadas y conmemoradas en la comisura que forman los labios besantes en la línea del horizonte, mundo e historia que ahora son albergados en la concavidad del beso. El horizonte es un beso sin confines visto desde dentro.

Si la noche es la corriente que arrastra, ¿qué somos nosotros? «Somos de agua». Nosotros no somos la noche, sino que estamos hechos de ella.

Así se explican las determinaciones opuestas. ¿Cuándo nuestras manos y nuestras palabras están llenas de noche y al mismo tiempo no pueden asirla ni nombrarla? Cuando, sin ser la noche, están hechas de ella.

Si la noche es desierto, nosotros somos de arena. Si es planicie, somos de hierba. Si es río, «somos de agua». ${ }^{43}$

El río, que fluye profundamente, es inasible y subterráneo, pero con su fugacidad y ocultamiento, con su fluidez y soterramiento, da asentamiento, consistencia y solidez a lo más manifiesto: la arena que se concentra, la hierba que descansa, el cielo que se serena, la niebla que se extiende y el océano que late. Todos estos elementos definen extensiones: desiertos, cielos, planicies, océanos, masas nubosas, como si su expansión se agradeciera a un acto poético que, a modo de foco, se ha reducido a un punto haciéndose así invisible. A este juego poético de concentrarse para hacer expandir, o de ocultarse para hacer manifiesto, aludirá el último poema con su título, «Epifanía», y su personaje de «la reina oculta».

\section{IV.3.2. REVALORIZACIÓN DE LA ESTANCIA TRAS LA RECAPITULACIÓN}

De la segunda parte del poemario conocemos la descripción de la buhardilla como un "hueco de caída», es decir, como un pozo. No es difícil hacer la asimilación pozo-claustro-taller-laboratorio como ámbitos y representaciones de una "concentración creadora», magnéticas simas que

43 Ibídem,p. 67. 
abisman y difunden y nos sumen en una «absorción desveladora». Y es que la concentración y abstracción mental, que es una llave que abre puertas, cuando es muy intensa se asemeja a la inconsciencia, y así salimos de ella como si despertáramos de un sueño.

Sumirse en la abstracción exige olvidarse de sí mismo. Eso es muy arduo, tan arduo como el frío mismo, porque lo más difícil en filosofía es pensar sin pensarse a sí mismo. Metafóricamente, para entrar en la buhardilla quizá fue preciso dejar a la puerta no solo la vida anterior, sino también su recuerdo.

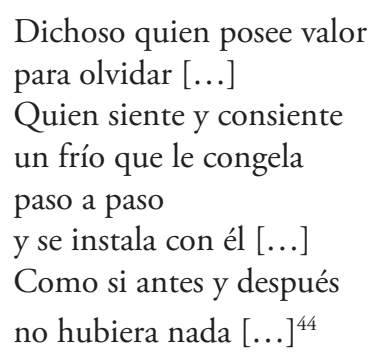

Sin embartgo, cuando salimos de la abstracción como quien despierta de un sueño, o metafóricamente cuando se sale de la buhardilla, nos traemos la memoria de lo que se ha llegado a ver, a entender y a vivir dentro. Es más, no es posible desprenderse ya de ese recuerdo, no porque la vivencia haya fortalecido nuestra capacidad memorística, sino porque lo avistado es en sí mismo inolvidable. ¿Y qué es lo avistado? La buhardilla es el espacio donde la noche luminosa ilumina lo que ningún día alumbra: $e l$ ser que no somos pero del que estamos hechos y que de ordinario no vemos, una de cuyas metáforas es el agua. Una vez que la noche luminosa nos ha permitido ver el ser del que estamos hechos, esa visión es ya inolvidable. Podremos salir de esa visión si abandonamos la buhardilla, ya solo porque la estancia en ella es cruel y ardua. Pero ya no podremos deshacernos de ese conocimiento. Ese tipo de conocimiento que, una vez alcanzado, es ya inolvidable porque se ha hecho parte de nosotros, es decir, porque a partir de ahora nosotros estamos hechos de él, en la gnoseología clásica se llama «hábito» o «thesaurus. Se parece a la memoria en que es un saber permanente e inolvidable que nos constituye y del cual estamos hechos,

44 Ibídem, p. 68. 
pero del que sin embargo no tenemos una constante conciencia expresa. Si llegamos a conocer que sin ser mar estamos hechos de agua, y que sin ser pozo ni buhardilla estamos hechos de noche de luz, entonces el agua y la noche son nuestros hábitos.

Este conocimiento habitual fue descrito ya en el primer apartado:

El momento es el mismo de siempre:

de nuevo despierto a esta oscuridad ${ }^{45}$

La permanencia de lo inolvidable, de lo que de ordinario no tenemos conciencia expresa pero que en todo momento podemos evocar, es el «siempre» de la oscuridad a la cual en ocasiones despertamos. A quien ha ganado ese conocimiento tras haber superado la ardua estancia podremos entonarle un «Beatus ille». ${ }^{46}$

\section{IV.3.3. Regreso PERTRECHAdo DE LA REVALORIZACión}

El confinamiento en la buhardilla ha sido duro y no se podía sobrellevar indefinidamente. Pero tampoco fue nunca ése su objetivo. Como si fuera una evocación de la parábola platónica de la caverna, en la que el liberado tras ver el sol vuelve a bajar a la oscuridad de la caverna para liberar a quienes nunca han conocido más que sombras, la poetisa baja también de la buhardilla después de que la noche de luz le ha hecho ver el ser del que está hecha. Pero cuando haya bajado, ¿qué podría contar de la noche? Quizá nada. Quien baja de la buhardilla es «el discreto», aquel que calla y «no quería decir cuanto sabía». ¿Es posible decir el pozo de los nombres a quienes no lo conocen? ¿Cómo, si no lo entenderían? Entonces el saber se convierte en una "pesada carga».

[...] el secreto era continuar haciendo

como si no supiera,

aunque sabiendo ${ }^{47}$

El último poema del poemario lleva por título «Epifanía». Comienza y termina con estos versos:

45 Ibidem,p. 30.

46 Ibidem,p. 68.

47 Ibídem,p. 69. 
La reina oculta

ha vuelto ${ }^{48}$

«Epifanía» significa revelación. Su etimología es epi-, por encima de, y fainein, «aparecer», «mostrar», «alumbrar». El mismo origen etimológico tienen palabras como faro o farol, fanático (etimológicamente «el deslumbrado y cegado»), fano (templo) o profano (lo que hay antes del templo), fenómeno (lo que aparece), fantasma (el aparecido), fantasía (imagen), y muchas más cuyo significado etimológico es muy evidente.

Epifanía es «aparecer por encima de» o «brillar por encima de». El brillo es lo que se muestra resplandeciendo y al mismo tiempo lo que alumbra.

En este poema, la epifanía como «aparecer por encima de» tiene el sentido de un regreso o reaparición. "Aparecer» es mostrarse, y "por encima de» es hacerlo de nuevo después de haberse ido.

Quien vuelve es la reina oculta. El ocultamiento es siempre una ausencia, al menos para la mirada. Pero el regreso de la reina oculta no hay que entenderlo en el sentido de que su marcha fue su ocultamiento y desaparición y ahora su regreso es su desvelamiento y aparición, de modo que al regresar deja de estar oculta y pasa a estar manifiesta. Sino que vuelve como reina oculta.

Volver como reina oculta es mostrarse sin salir del ocultamiento, manifestarse de modo que esa aparición sea imperceptible. Esa es la «epi-fanía» de la «reina oculta»: hacer manifestación del ocultamiento.

¿Quién hace de la manifestación ocultamiento? ¿Quién resplandece haciéndose invisible? ¿Quién es la reina oculta? En realidad ya lo sabemos desde la primera palabra del título del poemario: la luz.

«La reina oculta» es el epíteto de la luz, y así es como los últimos versos del poemario "vuelven» de nuevo al comienzo. «Rica», «majestuosa», «serena», «honda», «libre»: ¿¿no son atributos de la luz?

Pero la «reina oculta» es también la poetisa que ha descubierto en la buhardilla que, sin ser ella la luz de noche o la noche de luz, sin embargo sí está hecha de ella.

Ser bautizado en la luz de noche exige desprenderse de todos los contenidos, ya sean poseídos como objetos o sabidos como conocimientos

48 Ibídem, p. 73. 
o como recuerdos. Ese desprendimiento se puede representar metafóricamente como la subida por las escaleras que conducen a la buhardilla. A resultas de ese desprendimiento el poeta o la poetisa queda desposeído y vulnerado, pero precisamente "herido por nada». ¿Qué son las heridas, la «lanzada en las entrańas» o la "rasgadura de la túnica», sino la marca de ausencias?

\section{LA CONTRACUBIERTA: PUERTA DE SALIDA}

Cuando acabamos de leer el libro nos encontramos en la contracubierta con el breve poema encabalgado: «Podrías / buscar eternamente / eternamente hallar y perder el rastro». Si la portada del libro es como una ventana que al ser abierta nos da paso al interior, la contracubierta es como una puerta que al ser cerrada nos vuelve a dejar fuera. Ese poema, puesto en la contracubierta, casi se lee como el «Buscad y hallaréis» que Bach escribió al comienzo de uno de sus contrapuntos, como si estuviera dando la clave de un enigma. Si lo interpretamos así, el poema de la contracubierta parece advertirnos de que fuera del libro perdemos el rastro de la génesis del acto poético, e indirectamente nos está invitando a volver a entrar.

Según esta interpretación, al salir de la buhardilla cerrando la puerta, es decir, metafóricamente al cerrar el libro después de leerlo, perdemos algo que tenemos que volver a buscar reabriendo la puerta o la portada. Sin embargo, esta interpretación contradice la idea de que conocer la noche de luz es saber que estamos hechos de ella, de modo que ese conocimiento es inolvidable, y aunque no lo fuera su olvido ya no nos afectaría.

El poema nos dice literalmente que podríamos buscar, y que si buscáramos hallaríamos, pero al mismo tiempo perderíamos el rastro. La clave que resuelve el enigma de la contracubierta podría estar en el tiempo verbal: "podrías» está en condicional. Remite por tanto a una condición, a un presupuesto. ¿Bajo qué condición nos enredaríamos en una búsqueda desesperada? Una búsqueda es desesperada cuando está condenada a no encontrar nunca. Pero también cuando hallar es simultáneo e indiscernible de perder el rastro.

Los versos nos dicen también que el hallazgo no es puntual, sino eterno. Normalmente el hallazgo se produce al cabo de una búsqueda, sea ésta intencionada o no. Cuando volvemos a disponer de lo hallado, el propio acto 
de hallar termina. Normalmente el hallazgo es un punto entre la búsqueda y la disposición.

Pero este hallazgo simultáneo e indiscernible de la pérdida del rastro es eterno, es decir, permanente. No es un punto entre la búsqueda y la disposición, entre el rastro de lo buscado y la presencia de lo recuperado, sino que está por encima de la distinción entre rastro y presencia. El hallazgo permanente es superior a la oposición ausencia/presencia e inasequible desde ella.

¿Mas no sabemos ya, desde el mismísimo título del poemario, qué es aquello cuya presencia, claridad y disposición son indiscernibles de su ausencia, oscuridad y rastro? ¿Entendemos ahora que el poema de la contracubierta es una glosa del título en forma de enigma que solo desvelará quien cierra el libro tras haberlo leído, es decir, metafóricamente quien haya entrado y tras la estancia haya salido? ¿Cómo la puerta de entrada y la puerta de salida no habrían de ser la misma? 